\title{
Deoxyribonuclease Il $\alpha$ is required during the phagocytic phase of apoptosis and its loss causes perinatal lethality
}

\author{
RJ Krieser ${ }^{1}$, KS MacLea ${ }^{1}$, DS Longnecker ${ }^{2}$, JL Fields ${ }^{3}$, \\ S Fiering ${ }^{3}$ and A Eastman ${ }^{\star, 1}$ \\ ${ }^{1}$ Department of Pharmacology and Toxicology, Dartmouth Medical School, \\ Hanover, NH 03755, USA \\ 2 Department of Pathology, Dartmouth Medical School, Hanover, NH 03755 \\ USA \\ ${ }^{3}$ Department of Microbiology and Immunology, Dartmouth Medical School, \\ Hanover, NH 03755, USA \\ * Corresponding author: Alan Eastman, Department of Pharmacology and \\ Toxicology, Dartmouth Medical School, 7650 Remsen. Hanover, NH 03755, \\ USA. Tel: 603-650-1501; Fax: 603-650-1129; \\ E-mail: alan.eastman@Dartmouth.edu
}

Received 12.6.01; revised 12.2.02; accepted 18.3.02

Edited by G Nunez

\begin{abstract}
Deoxyribonuclease $\| l \alpha$ (DNase $\| l \alpha$ ) is one of many endonucleases implicated in DNA digestion during apoptosis. We produced mice with targeted disruption of DNase Il $\alpha$ and defined its role in apoptosis. Mice deleted for DNase Il $\alpha$ die at birth with many tissues exhibiting large DNA-containing bodies that result from engulfed but undigested cell corpses. These DNA-containing bodies are pronounced in the liver where fetal definitive erythropoiesis occurs and extruded nuclei are degraded. They are found between the digits, where apoptosis occurs, and in many other regions of the embryo. Defects in the diaphragm appear to cause death of the mice due to asphyxiation. The DNA in these bodies contains 3'hydroxylends and therefore stain positive in the TUNEL assay. In addition, numerous unengulfed TUNEL-positive cells are observed throughout the embryo. Apoptotic cells are normally cleared rapidly from a tissue; hence the persistence of the DNA-containing bodies and TUNEL-positive cells identifies sites where apoptosis occurs during development. These results demonstrate that DNase Il $\alpha$ is not required for the generation of the characterisitic DNA fragmentation that occurs during apoptosis but is required for degrading DNA of dying cells and this function is necessary for proper fetal development.
\end{abstract}

Cell Death and Differentiation (2002) 9, 956-962. doi:10.1038/ sj.cdd. 4401056

Keywords: apoptosis; endonuclease; NUC-1; phagocytosis; DNA digestion

Abbreviations: CAD, caspase-activated deoxyribonuclease; DCB, DNA containing bodies; DNase, deoxyribonuclease; H\&E, hematoxylin and eosin; ICAD, inhibitor of CAD; MEF, mouse embryonic fibroblasts; TUNEL, terminal deoxynucleotidyl transferase end labeling
Introduction

Apoptosis was first described in 1972 as a type of shrinkage necrosis observed in tissue sections under the microscope. ${ }^{1}$ A dead cell lost contact with neighboring cells, shrank, and condensed its chromatin. This was a fairly rare observation, and it is now known that neighboring cells phagocytoze apoptotic cells thereby rapidly removing the evidence of a cell death event. DNA from apoptotic cells is fragmented into multimers of $180 \mathrm{bp}$ consistent with nuclease cleavage in the internucleosomal regions. Many key proteins involved in the apoptotic pathway have subsequently been identified. These include the caspase family of proteases and the Bcl-2 family of apoptotic regulators. ${ }^{2,3}$ However, the involvement of a specific endonuclease in this process has yet to be fully established. Many endonucleases have been implicated in this process, such as caspase-activated DNase (CAD) and DNase I. ${ }^{4,5}$ CAD was reported to be associated with an inhibitor molecule, inhibitor of caspase-activated DNase (ICAD), that is cleaved by caspases during apoptosis to release the active endonuclease. ${ }^{4,6}$ Knockout mouse models with disruptions of either the CAD/ICAD system or DNase I result in visually normal mice..$^{7-9}$ The disruption of the CAD system prevented DNA fragmentation in thymocytes undergoing apoptosis in culture, but DNA fragmentation occurred in the thymus in vivo after phagocytosis of the apoptotic cell. DNase I-/ - mice were healthy when young but several died between 6-8 months of age. Analysis of DNase I-/- mice revealed the presence of anti-nuclear antigens and glomerulonephritis indicative of a lupus-like syndrome in older mice.

The limited phenotypes observed after the disruptions of the ICAD/CAD system or DNase I indicate that another endonuclease likely has a role in apoptosis, and that the use of a specific endonuclease may be dependent on the cell type or insult used to induce apoptosis. Work done in this laboratory originally implicated the acid-activated DNase II as having a potential role in apoptosis, and consequently established intracellular acidification as a biochemical event consistently observed as cells undergo apoptosis. $^{10,11}$

We previously characterized the human and mouse genes encoding DNase II. ${ }^{12,13}$ With the subsequent identification and cloning of a human homolog designated DNase $I I \beta,{ }^{14}$ the original gene is now referred to as DNase $\| \alpha$. DNase $\| \alpha$ is ubiquitously expressed while DNase $\| \beta$ is primarily expressed in the human salivary glands. Of note for these studies, mice express DNase II $\beta$ in the liver, a fact that may be attributed to expression of the neighboring gene, uricase. Humans do not express DNase $I I \beta$ in the liver, nor do they express uricase, which is a nonfunctional pseudogene. Both DNase II genes are highly homologous to three genes in $C$. elegans, ${ }^{13,14}$ one of which, nuc-1, appears to be involved in DNA digestion of dying cells before engulfment. ${ }^{15}$ However, nuc-1-defective nematodes 
show no developmental defects. We produced mice with targeted disruption of DNase $/ / \alpha$ and show that it is involved in the phagocytic phase of apoptosis, and that digestion of DNA from dying cells is essential for viability.

\section{Results and Discussion}

The phage DNA used to sequence the mouse gene ${ }^{13}$ was used to create a mouse that was null for DNase Il $\alpha$ (Figure 1). DNase $I l \alpha+/-$ mice were identified and mated. These
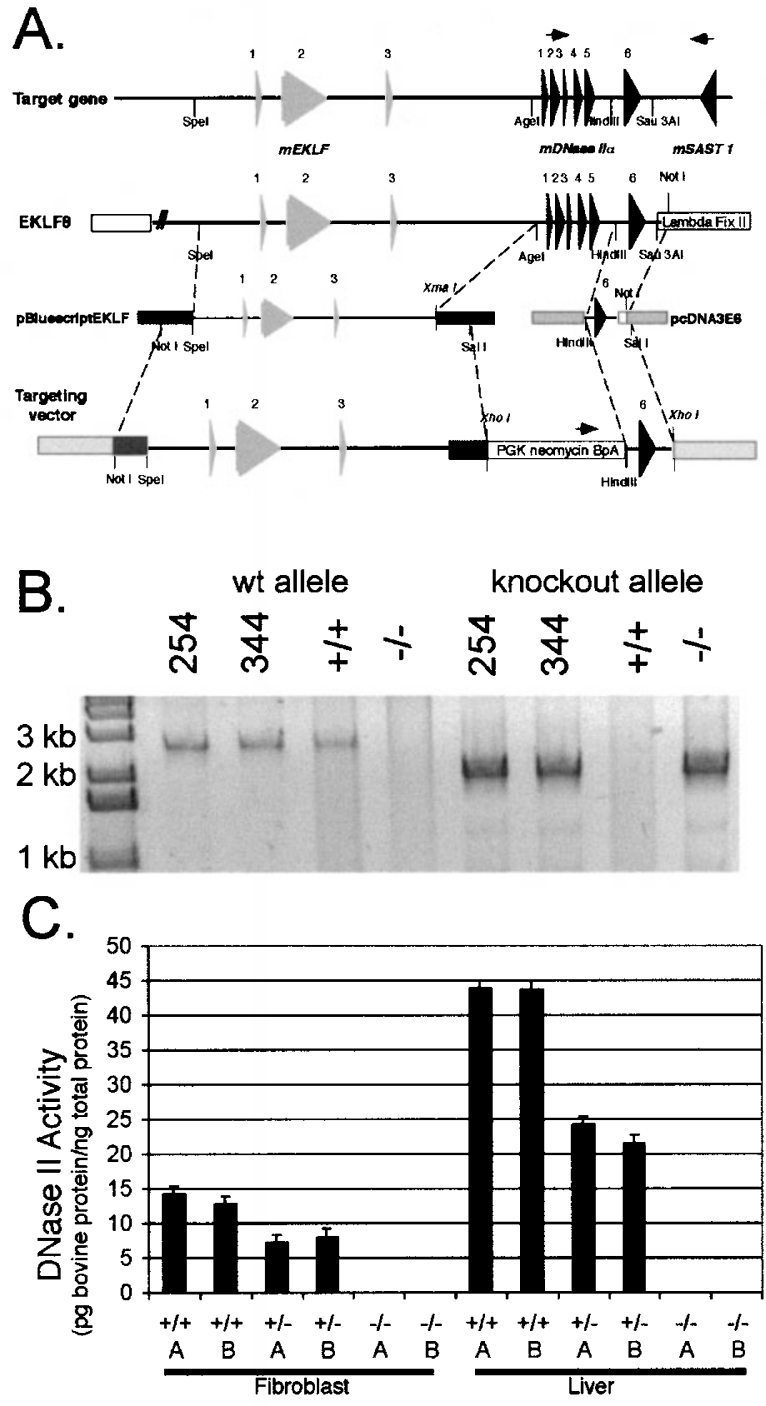

Figure 1 Production of DNase Il $\alpha-/-$ mice. (A) The phage DNA used to sequence the mouse genes ${ }^{13}$ was used to create a mouse that was null for DNase Il $\alpha$. A targeting vector aimed at deleting the first five exons of mDNase Il $\alpha$ was created using the strategy shown. (B) This vector was transfected into ES cells that were subsequently clonally selected for neomycin resistance encoded by the vector. The clones were screened by PCR using primers (arrows above genes in Figure 1A) that amplify only the wild-type or knockout alleles. Analysis of DNA from two heterozygous ES clones are shown along with wild-type and subsequent knockout mouse DNA. (C) Mouse embryo fibroblasts and E15.5 livers from $+/+,+/-$, and $-/$ - embryos were examined for acid endonuclease activity. The activity is expressed as equivalent amount of bovine DNase II matings produced DNase $\mathrm{Il} \alpha+/+$ and $+/-$ mice at a ratio of approximately $1: 2$. No live DNase $\| \alpha-/-$ mice were found at this time. Inspection of a new litter showed two dead neonates. These mice were genotyped and shown to be DNase Il $\alpha-/-$. They appeared normal upon gross inspection, with all limbs intact and external processes formed, however they appeared anemic. The mice were fixed, embedded in paraffin and sectioned for histological examination. Examination of hematoxylin and eosin (H\&E) stained sections showed the presence of large bodies of hematoxylin-stained material. These bodies were most prominent in the liver, but were also observed in many other tissues (see below). In addition, a thin and fragmented diaphragm was observed. The lungs had not inflated and a diaphragmatic hernia was noted, potentially due to the malformed diaphragm.

Mice were usually born on day 19; therefore, day 18.5 embryos were examined to determine if death was occurring late in development or after birth. Three - / embryos and three $+/+$ embryos were removed and examined grossly. Two of the three $-/$ - embryos showed movement, indicating that they were still viable at this late developmental stage. Although the knockout embryos appeared anemic, the fact that they were still alive at this late stage of fetal development suggests that they die at birth due to the dysfunctional diaphragm and resulting asphyxiation.

Considering reports of other acid endonuclease, and in particular DNase $\| \beta$ in mouse liver, ${ }^{14,16}$ we examined whether the genetic disruption of the DNase Il $\alpha$ gene results in the complete loss of acidic endonuclease activity. Therefore, livers from E15.5 animals were analyzed for acid endonuclease activity. The $+/+$ livers had a high level of activity, the +/ - livers had an intermediate level of activity, and the $-/$ - livers had no detectable activity (Figure 1C). This indicates that the acid endonuclease activity found in the embryonic liver is entirely due to DNase Il $\alpha$. Mouse embryo fibroblasts (MEFs) were also examined for DNase II activity. The $-/-$ MEFs exhibited no acid endonuclease activity, while the $+/-$ MEFs had approximately $50 \%$ of the activity of $+/+$ MEFs (Figure 1C). The lack of any acid endonuclease activity in the DNase Il $\alpha-/-$ MEF cells indicates that this gene is responsible for acid endonuclease activity in these cells.

Timed pregnancies were conducted to better define the morphological changes that were occurring as well as to confirm the cause of death of these animals. Embryos were examined at days $13.5,14.5$, and 15.5. H\&E staining showed the presence of large clumps of hematoxylin stained material (Figure 2). Feulgen and Hoechst 33342 staining of comparable sections indicated that these bodies contained DNA. These large DNA-containing bodies (DCBs) were observed in many tissues of the $-/-$ embryos, but were completely absent in wild-type and heterozygous mice (Figure 2). The DCBs were frequently more than 10-fold larger than normal nuclei and probably derive from a phagocytic cell engulfing cell corpses but failing to digest their DNA. In the day $13.5-/-$ embryos, pronounced DCBs are observed in the liver, diaphragm, brain, spinal cord, adrenal gland, and many other tissues (Figure 2). The 

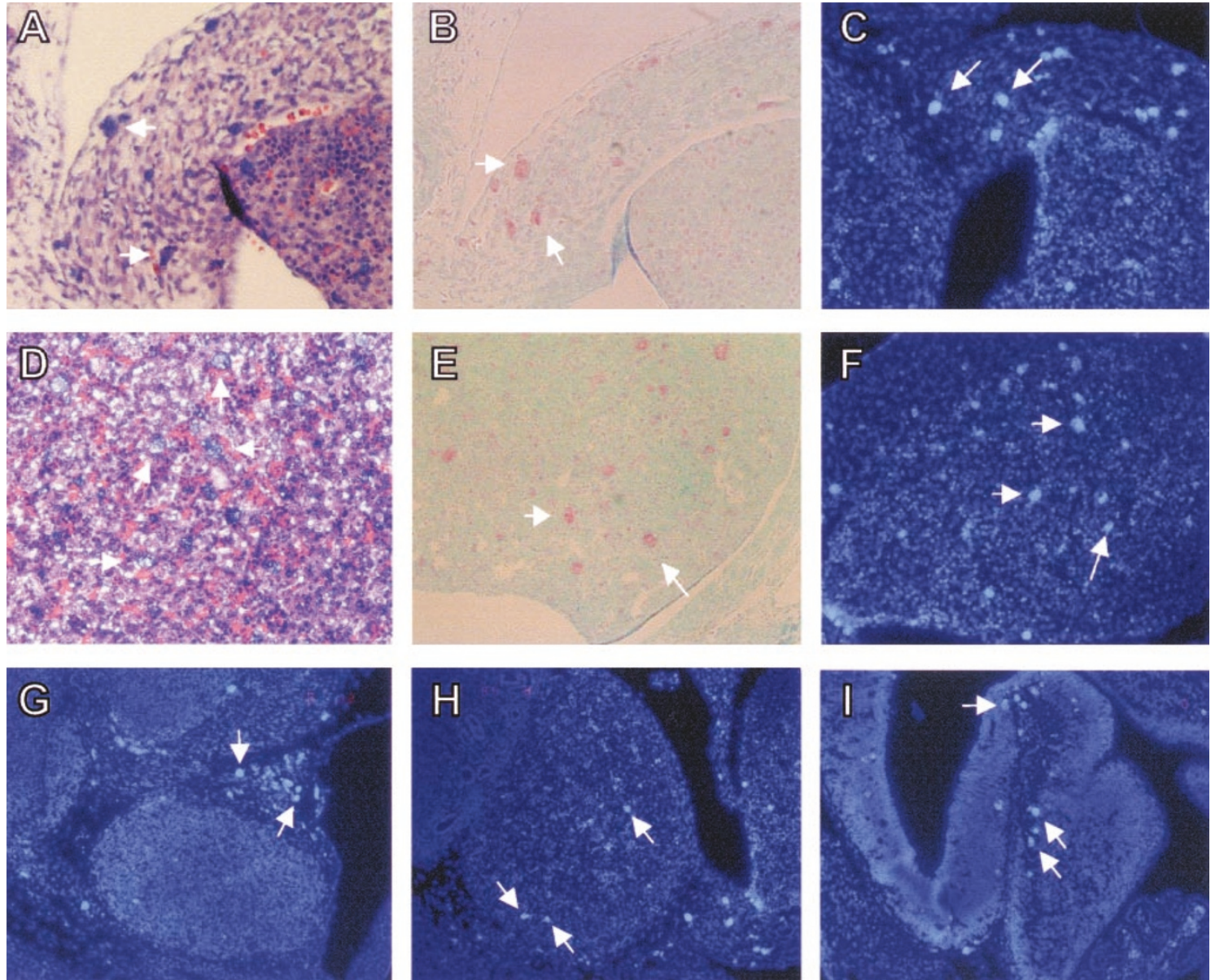

Figure 2 Histological analysis of tissues from DNase Il $\alpha-/$ - mice. E 13.5 mouse embryos were fixed in $10 \%$ formalin and embedded in paraffin. Five $\mu \mathrm{m}$ thick sections were stained using hematoxylin and eosin (H\&E), methyl green and Feulgen dye, or Hoechst 33342. DCBs are observed in $-I-$ diaphragm (A, B, \& C), stained with H\&E, methyl green and Feulgen, and Hoechst 33342 respectively. DCBs are present in $-/-$ liver (D, E, \& F), stained with H\&E, methyl green and Feulgen, and Hoechst 33342 respectively. DCBs are also present in the cortex of $-/$ - thymus gland $(\mathbf{G})$, adrenal gland $(\mathbf{H})$, and cerebellum (I) stained with Hoechst 33342. Arrows point out DCBs

DCBs appeared in the base of the diaphragm and throughout the central nervous system of E13.5 -/embryos (Figure 2). The DCBs probably contribute to the malformation of the diaphragm, which would explain the death of the mice by asphyxiation at birth.

The liver contains the highest number of DCBs. During fetal development, definitive hematopoiesis first occurs in the liver. Erythrocytes extrude their nuclei as they differentiate and phagocytic cells remove these nuclei. The lack of degradation of erythrocyte DNA in - /- mice presumably results in the high number of DCBs present in the developing liver. This defect in hematopoiesis was also reported in a parallel study ${ }^{17}$ although our results suggest that the resulting anemia is not the actual cause of death.

DCBs are readily observable in tissues where the frequency of apoptosis and therefore phagocytosis of apoptotic corpses is high. Apoptosis is known to occur during normal E11 and E12 in the cerebellum and choroid plexus ${ }^{18}$. Apoptosis is normally undetectable in these tissues at E14. The DNase Il $\alpha-/$ - embryos show DCBs in these tissues (Figure 2) which persist after E14. DCBs thus demonstrate areas where apoptosis has occurred during development, the evidence of which is normally removed rapidly by phagocytes.

One well-defined region of apoptosis that occurs during embryogenesis and development results in the removal of the webbing between the digits, a process that takes place between E12.5 and E15. ${ }^{19}$ Examination of the interdigital region of E15.5 embryos indicate the presence of DCBs, whereas they are absent in $+/+$ and $+/-$ controls (Figure $3)$. To determine if the DCBs were derived from apoptotic cells, we used the TUNEL assay that labels fragmented DNA that has $3^{\prime}$ hydroxy ends. The DCBs in the interdigital region of day $14.5-/-$ embryos were positive for TUNEL staining, indicating that they are indeed derived from apoptotic DNA (Figure 3).

Staining with the TUNEL assay clearly shows the distribution of DCBs throughout the entire - /- embryo (Figure 4A and B). The liver showed very intense staining in the $-/-$ embryo due to the high frequency of TUNELreactive ends in the DCBs found there. Other areas of the $-/$ - embryo also are intensely TUNEL-positive such as 

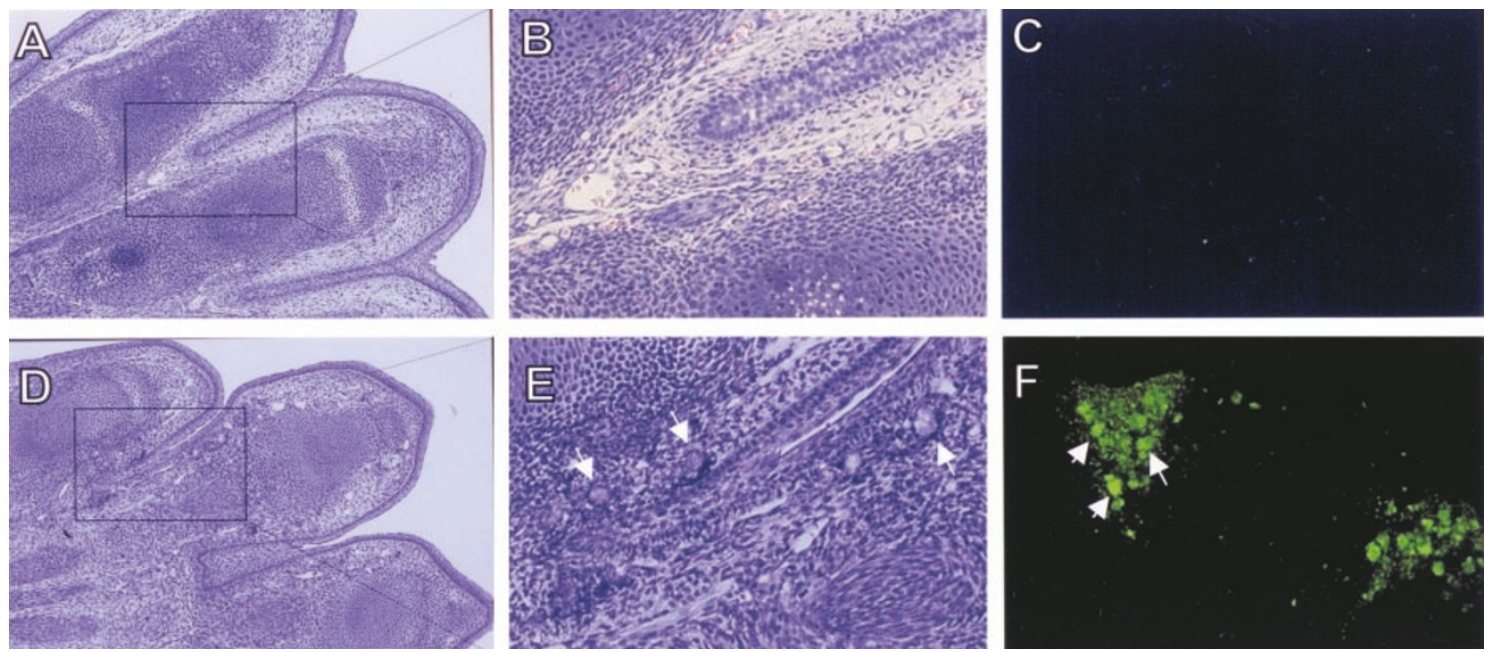

Figure 3 Comparison of the interdigital region of wild-type and DNase $\| \alpha-/-$ mice. E15.5 $+/+(\mathbf{A}, \mathbf{B})$ and $-/-(\mathbf{D}, \mathbf{E})$ embryos were fixed, embedded in paraffin and $5 \mu \mathrm{m}$ sections were mounted and stained with H\&E. E14.5 $+/+(\mathbf{C})$ and $-/-(\mathbf{F})$ embryos were frozen, and $10 \mu \mathrm{m}$ sections were cut and stained for TUNEL; $\mathrm{F}$ is a high magnification of the mouse paw seen in Figure 4B. Arrows point out DCBs

the interdigital regions, and regions in the brain and spinal cord. In contrast, there was little staining in the $+/+$ embryo, the most obvious tissue being liver, but this is due to endogenous biotin binding to the FITC-conjugated avidin used in the TUNEL assay and is not due to DNA breaks. Heterozygous embryos were indistinguishable from DNase Il $\alpha+/+$ embryos.

Interestingly, higher magnification of many tissues revealed a very high frequency of TUNEL-positive cells that are not restricted to DCBs. An example is shown in the brain (Figure 4C). The apoptotic nuclei are intensely TUNEL-positive and shrunken compared to normal nuclei. This is in contrast to the DCBs, which are much larger than normal nuclei and contain more diffuse TUNEL-stained DNA. DNase Il $\alpha$ leaves $3^{\prime}$ phosphate ends on DNA, which are not substrates for TUNEL. Hence DNase Il $\alpha$ may mask the ends of apoptotic DNA in $+/+$ and $+/-$ cells. A similar result was reported for nuc-1 mutant $C$. elegans. Many more TUNEL-positive cells were observed in nuc-1 embryos compared to wild-type demonstrating a role of NUC-1 in degrading fragmented DNA in apoptotic cells. ${ }^{15}$ By use of engulfment-defective mutants, NUC-1 has been shown to act in the dying cells, but it was thought that an additional endonuclease was required after engulfment. Our results clearly show that DNase $\| \alpha$ is required for DNA degradation of an engulfed cell. The results further suggest that DNase Il $\alpha$ may function like NUC-1 to mask the ends of DNA degraded by another apoptotic endonuclease prior to the engulfment process.

Our laboratory has previously shown that cells undergo intracellular acidification concurrent with apoptosis. ${ }^{20,21}$ This acidification may activate the cellular DNase $\| \alpha$, contributing to the DNA degradation process and masking of TUNEL reactive ends. An alternative interpretation of our results is that the apoptotic cells may persist much longer than normal because the phagocytes have become dysfunctional after engulfing a few corpses and failing to degrade their DNA. However, it is clear that the TUNEL staining defines numerous areas where apoptosis is occurring in the embryo. Our results therefore show that DNase $I l \alpha$ is not required for the initial DNA breaks in the TUNEL-positive tissues of the -/- embryos.

Interestingly, DCBs were not observed in certain tissues, such as the developing heart, lung, intestine, stomach, retina, pancreas, kidney, or skeletal muscle. The lack of DCBs in tissues such as the heart, where apoptosis is involved in remodeling during murine embryogenesis ${ }^{22}$ indicates that other endonucleases either fully degrade the DNA in the apoptotic cell or are present in resident macrophages in these tissues. DNase II has been thought to have a role in the nuclear degeneration of lens cells. ${ }^{21}$ Lens cell nuclear degeneration still occurred in DNase Il $\alpha$ - / - embryos, indicating that another acid endonuclease, possibly L-DNase II, may function in this role. ${ }^{23}$

The use of a specific DNase for apoptotic and/or phagocytic DNA digestion could be cell type specific. Our evidence in knockout embryos has indicated tissues, such as the liver, diaphragm, and CNS, in which DNase Il $\alpha$ may have a role. The lack of the proper disposal of apoptotic cells has been hypothesized to play a role in disease. Patients with systemic lupus erythematosus have impaired engulfment and degradation of apoptotic cells. ${ }^{24}$ These apoptotic remnants then serve as immunogens that produce autoreactive lymphocytes, and are antigens for immune complex formation. In addition, the phenomenon of the lupus erythematosus cell (LE cell) in the blood appears similar to the DCBs observed in the tissues of the DNase Il $\alpha$ knockout mice. The LE cell is thought to result from the phagocytosis of apoptotic bodies by granulocytes. The engulfed nucleoid structures are TUNEL-positive. ${ }^{25}$ The similarity of the nucleoid structures of the LE cell to DCBs in the DNase II $\alpha-/$ - embryos may indicate an impairment of DNase Il $\alpha$ in lupus erythematosus.

Our observations indicate that DNase Il $\alpha$ plays a role in the proper removal of apoptotic nuclei during fetal development. Interestingly, we observed the presence of 

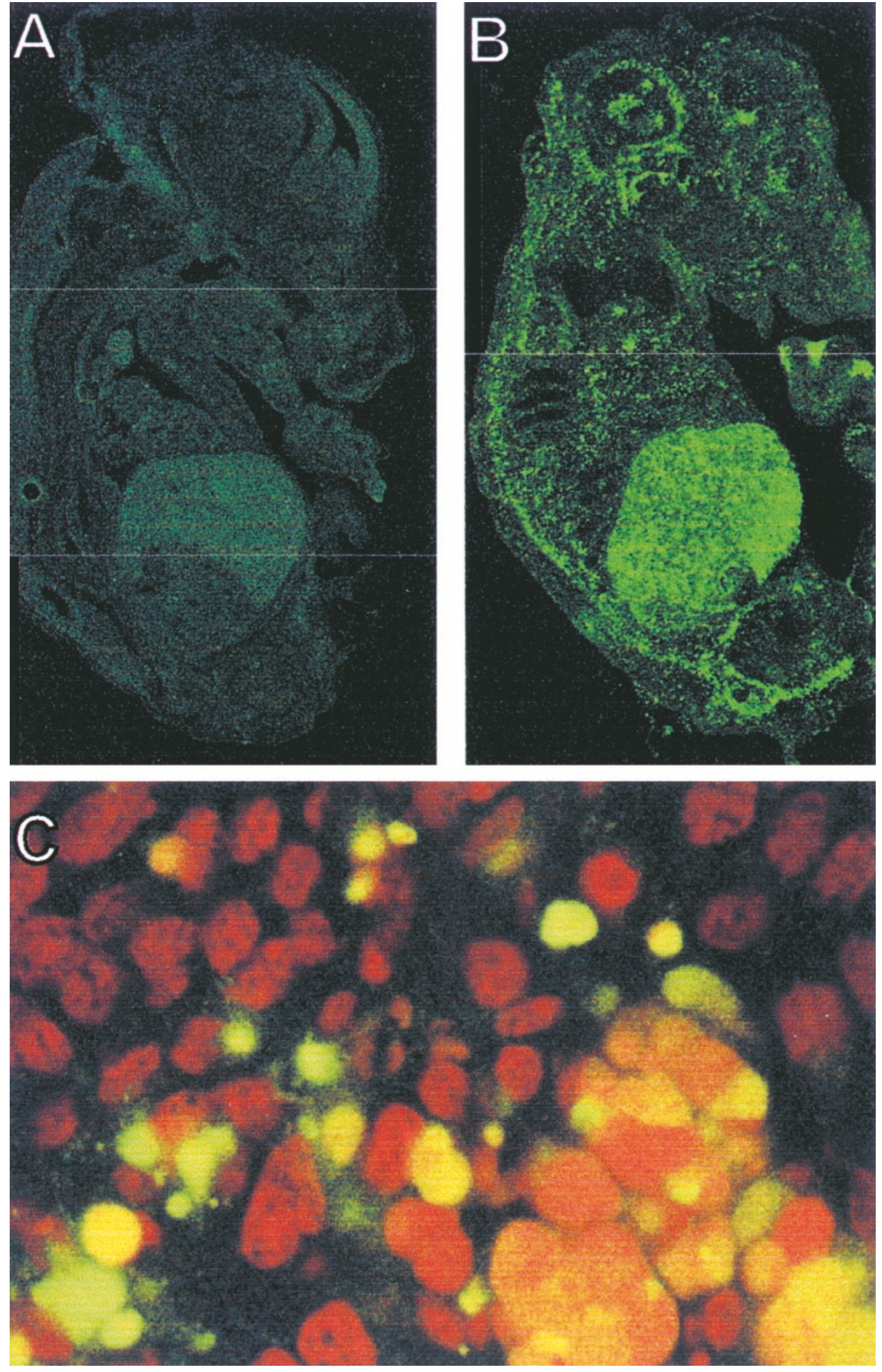

Figure 4 DNase ll $\alpha$ disruption results in numerous TUNEL labeled cells. E14.5 $+/+$ (A) and $-/-($ B) embryos were cryoprotected in $30 \%$ sucrose in PBS, frozen in OCT compound, and examined with TUNEL. A higher magnification of the paw in B is shown in Figure 3F. (C) High resolution confocal image of E14.5 - / - brain, along the edge of the developing pons, examined with TUNEL (green) and counterstained with propidium iodide (red). Cells staining intensely green show TUNEL positivity which overrides the propidium iodide costaining. The large yellow/orange regions reflect DCBs with less TUNEL positivity such that the propidium iodide staining is also observed 
TUNEL-positive DCBs and persistent TUNEL-positive cells in many tissues in the $-/-$ mouse embryo. The appearance of DCBs and TUNEL-positive cells defines tissues during development where apoptosis is occurring. The DNase II $\alpha-/-$ mice also demonstrate that the proper removal of apoptotic debris is required for their viability.

\section{Materials and Methods}

\section{Vector construction}

The knockout targeting vector was constructed as outlined in Figure 1A. Mouse genomic fragments were isolated from EKLF8, a phage clone containing erythroid kruppel like factor (EKLF) and mDNase Il $\alpha$ (kindly provided by Dr. Stuart Orkin), and previously mapped in this laboratory. ${ }^{13}$ EKLF8 was digested with Hindlll and Notl, and the $1.2 \mathrm{~kb}$ fragment containing exon 6 of DNase $I l \alpha$ was ligated into the pcDNA3.0 vector (Invitrogen, Carlsbad, CA, USA) digested with the same enzymes (termed pcDNA3E6). EKLF8 was also digested with Spel and Agel and the $8 \mathrm{~kb}$ fragment containing the EKLF gene was ligated into Spel and Xmal digested Bluescript (termed pBluescriptEKLF). The Hindlll-Sall fragment of pcDNA3E6 and the Notl-Sall fragment of Bluescript EKLF were cloned into the respective sites in PGKneoBpA to produce the targeting vector.

\section{Embryonic stem cell production}

The DNase Il $\alpha$ targeting vector was linearized by digestion with Notl. Fifteen $\mu \mathrm{g}$ of linearized vector was electroporated into murine $129 \mathrm{ES}$ cells and plated onto two feeder plates and selected in $180 \mu \mathrm{g} / \mathrm{ml}$ G418. Ninety-six colonies were picked from each plate and expanded. DNA was isolated from each colony and screened for homologous recombination of the vector within exon 6 of DNase Il $\alpha$ via PCR utilizing a primer located in the neighboring gene SAST-1, AAGCCTGAAGCAGGGTTGAA, and a primer within the inserted neomycin resistance gene, TAAAGCGCATGCTCCAGACT. The wildtype allele was amplified using the SAST-1 primer and a primer within the exons of mDNase $\| \alpha$ to be deleted, ATGGGCATACGAAGGGTGAG. The wild-type allele gave a PCR band of $2 \mathrm{kbp}$, while the deleted allele gave a band of $2.8 \mathrm{kbp} .192 \mathrm{ES}$ colonies were screened by PCR and three were found to produce positive bands for the knockout allele (Figure 1B; one clone not shown). These bands were cloned and sequenced confirming that they were homologous recombinants. Southern analysis was used to confirm homologous recombination within the EKLF region used in the knockout vector. ES cell DNA was digested with Spel, electrophoresed on an agarose gel, and transferred to a Genescreen II membrane. A radiolabeled probe specific to murine EKLF was hybridized to the membrane. Autoradiography was used to detect hybridization. The probe hybridized to a $9 \mathrm{~kb}$ band in the three ES clones and a larger band from the wild-type allele in all three ES clones as well as in 129 control DNA (data not shown).

\section{Generation of DNase II -I- mice}

Chimeric mice were generated by injection of blastocysts with DNase II +/- ES clones 344 and 254. The resulting chimeric mice were backcrossed to C57BL/6 mice. Germline transmission was detected by PCR of DNA isolated from tail snips of the offspring (for example, Figure 1B). DNase II +/-mice were mated to produce DNase II -/progeny.

\section{Timed pregnancies}

DNase II $+/$ - mice were mated in the late afternoon and the next morning examined for the presence of copulatory plugs. Midday on the day that plugs were detected was designated E 0.5. The uterus was removed at specified times thereafter and embryos dissected from the uterus for analysis. The yolk sac or tail from each embryo was retained for DNA isolation and genotyping. The embryo was then fixed in a solution of $10 \%$ formalin in phosphate buffered saline (PBS). The embryos were embedded in paraffin and sagittal sections were prepared for histological examination.

\section{MEF isolation and culturing}

Heterozygous mice were mated and embryos were harvested at $\mathrm{E}$ 12.5 and washed in cold PBS. The yolk sac was retained for DNA isolation and analysis from each embryo. The head and liver were removed from each embryo. The remainder of the carcass was placed in the barrel of a $3 \mathrm{ml}$ syringe with an 18 gauge sterile needle attached. $0.5 \mathrm{ml}$ of sterile PBS was added, the plunger was replaced, and the carcass was expelled into a $60 \mathrm{~mm}$ culture dish and redrawn 4-5 times to break it into smaller bits. Five $\mathrm{ml}$ of DMEM with $10 \%$ fetal bovine serum and antibiotics was added. The cells were trypsinized after 2 days and replated into a larger flask to grow a large population of cells. These cells were split for further use and frozen stocks were made.

\section{DNase II activity assay}

Intact liver or isolated cells were lysed in assay buffer $(100 \mathrm{mM}$ sodium acetate $\mathrm{pH}$ 5.0, $20 \mathrm{mM}$ EDTA, $2 \mathrm{mM} \mathrm{N}$-ethylmaleimide, $1 \mathrm{mM}$ PMSF, and $1 \mu \mathrm{g} / \mathrm{ml}$ pepstatin A), snap frozen, thawed and needle sheared 10 times through a $21 \mathrm{~g}$ needle. The cell lysate was then assayed for endonuclease activity using the single radial enzyme diffusion method. ${ }^{26}$ Radial diffusion diameters were compared to serial dilution of bovine DNase II (Sigma, St. Louis, MO, USA).

\section{Terminal deoxynucleotidyl transferase end labeling (TUNEL)}

Embryos were harvested and cryoprotected in 30\% sucrose in PBS for 3 days. Embryos were frozen in OCT compound (Sakura, Terrance, CA, USA) and stored at $-80^{\circ} \mathrm{C}$. Sections $(10 \mu \mathrm{m})$ were cut, mounted on slides, and dried overnight. Tissues were fixed in $2: 1$ ethanol: acetic acid for $10 \mathrm{~min}$ at $-20^{\circ} \mathrm{C}$, washed twice with PBS, and incubated with enzyme buffer (TUNEL reaction buffer, $0.1 \mathrm{mM}$ dithiothreitol, $1 \mathrm{mM} \mathrm{CoCl}_{2}$, with 5 units of terminal transferase (Roche, Indianapolis, IN, USA) and $0.5 \mathrm{nmol}$ biotinylated-dUTP) in a humid chamber for $30 \mathrm{~min}$ at $37^{\circ} \mathrm{C}$. Slides were washed twice with PBS, and incubated with staining buffer $(4 \times$ SSC, $0.1 \%$ Triton X-100, $5 \%$ nonfat dry milk $2.5 \mu \mathrm{g} / \mathrm{ml}$ avidin-FITC) for $30 \mathrm{~min}$ at room temp. The slides were washed twice with PBS, $0.1 \%$ Triton X-100, counterstained with Hoechst $33342(1 \mu \mathrm{g} / \mathrm{ml})$ or propidium iodide $(100 \mu \mathrm{g} / \mathrm{ml})$, and visualized by confocal or fluorescent microscopy.

\section{Acknowledgments}

This study was supported by a research grant from NIH (CA50224), a Cancer Center Support Grant to the Norris Cotton Cancer Center (CA23108) and a grant from the Hitchcock Clinic. We thank the Dartmouth Transgenic facility, Neema Ganju, Alice Givan of The Herbert C. Englert Cell Analysis Laboratory, and Christine Hodorowsky of the 
Dartmouth Hitchcock Research Pathology Core Facility for assistance with this study.

\section{References}

1. Kerr JFR, Wyllie AH and Currie AR (1972) Apoptosis: a basic biological phenomenon with wide-ranging implications in tissue kinetics. Br. J. Cancer 26: 239-257

2. Alnemri ES, Livingston DJ, Nicholson DW, Salvesen G, Thornberry NA, Wong WW and Yuan J (1996) Human ICE/CED-3 protease nomenclature. Cell 87: 171

3. Hengartner MO and Horvitz HR (1994) C. elegans cell survival gene ced-9 encodes a functional homolog of the mammalian proto-oncogene bcl-2. Cell 76: 665-676

4. Enari M, Sakahira H, Yokoyama H, Okawa K, Iwamatsu A and Nagata S (1998) A caspase-activated DNase that degrades DNA during apoptosis, and its inhibitor ICAD. Nature 391: 43-50

5. Peitsch MC, Polzar B, Tschopp J and Mannherz HG (1994) About the involvement of deoxyribonuclease I in apoptosis. Cell Death Different 1: 1-6

6. Sakahira H, Enari M and Nagata S (1998) Cleavage of CAD inhibitor in CAD activation and DNA degradation during apoptosis. Nature 391: 96-99

7. Mcllroy D, Tanaka M, Sakahira H, Fukuyama H, Suzuki M, Yamamura K, Ohsawa Y, Uchiyama $Y$ and Nagata S (2000) An auxiliary mode of apoptotic DNA fragmentation provided by phagocytes. Genes \& Dev. 14: 549-558

8. Zhang J, Lee H, Lou DW, Bovin GP and Xu M (2000) Lack of obvious 50 kilobase pair DNA fragments in DNA fragmentation factor 45-deficient thymocytes upon activation of apoptosis. Biochem. Biophys. Res. Commun. 274: 225-229

9. Napirei M, Karsunky H, Zevnik B, Stephan H, Mannherz HG and Moroy T (2000) Features of systemic lupus erythematosus in DNase1-deficient mice. Nature Genet. 25: 177-181

10. Barry MA and Eastman A (1993) Identification of deoxyribonuclease II as an endonuclease involved in apoptosis. Arch. Biochem. Biophys. 300: 440-450

11. Barry MA and Eastman A (1992) Endonuclease activation during apoptosis: the role of cytosolic $\mathrm{Ca}^{2+}$ and $\mathrm{pH}$. Biochem. Biophys. Res. Commun. 186: 782-789

12. Krieser RJ and Eastman A (1998) The cloning and expression of human deoxyribonuclease II: a possible role in apoptosis. J. Biol. Chem. 273: 3090930914

13. Krieser RJ and Eastman $A$ (2000) Structure and chromosomal localization of the murine deoxyribonuclease II gene. Gene 252: 155-162

14. Krieser RJ, MacLea KS, Park JP and Eastman A (2001) The cloning, genomic structure, localization, and expression of human deoxyribonuclease II $\beta$. Gene 269: $205-216$
15. Wu YC, Stanfield GM and Horvitz HR (2000) NUC-1, a Caenorhabditis elegans DNase II homolog, functions in an intermediate step of DNA degradation during apoptosis. Genes \& Dev. 14: 536-548

16. Shiokawa $D$ and Tanuma $S$ (1999) DLAD, a novel mammalian divalent cationindependent endonuclease with homology to DNase II. Nucleic Acids Res. 27: 4083-4089

17. Kawane K, Fukuyama H, Kondoh G, Takeda J, Ohsawa $Y$, Uchiyama $Y$ and Nagata S (2001) Requirement of DNase II for definitive erythropoiesis in the mouse fetal liver. Science 292: 1546-1549

18. van den Eijnde SM, Lips J, Boshart L, Vermeij-Keers C, Marani E, Reutelingsperger CPM and De Zeeuw CI (1999) Spatiotemporal distribution of dying neurons during early mouse development. Eur. J. Neuroscience 11:712724

19. Wood W, Turmaine M, Weber R, Camp V, Maki RA, McKercher SR and Martin P (2000) Mesenchymal cells engulf and clear apoptotic footplate cells in macrophageless PU.1 null mouse embryos. Development 127: 5245-5252

20. Li $\mathrm{J}$ and Eastman A (1995) Apoptosis in an IL-2-dependent cytotoxic T lymphocyte cell line is associated with intracellular acidification: role of the $\mathrm{Na}^{+}$/ $\mathrm{H}^{+}$-antiport. J. Biol. Chem. 270: 3203-3211

21. Reynolds JE, Li J and Eastman A (1996) Detection of apoptosis by flow cytometry of cells simultaneously stained for intracellullar pH (carboxy SNARF-1) and membrane permeability (Hoechst 33342). Cytometry 25: 349-357

22. Abdelwahid E, Pelliniemi LJ, Niinikoski H, Simell O, Tuominen J, Rahkonen $O$ and Jokinen $E$ (1999) Apoptosis in the pattern formation of the ventricular wall during mouse heart organogenesis. Anat. Record 256: 208-217

23. Navarro P, Valverde AM, Benito M and Lorenzo M (1999) Activated Ha-ras induces apoptosis by association with phosphorylated Bcl-2 in a mitogenactivated protein kinase-independent manner. J. Biol. Chem. 274: 1885718863

24. Lorenz H-M, Herrmann M, Winkler T, Gaipl U and Kalden JR (2000) Role of apoptosis in autoimmunity. Apoptosis 5: $443-449$

25. Schmidt-Acevedo S, Perez-Romano B and Ruiz-Argüelles A (2000) 'LE Cells' result from phagocytosis of apoptotic bodies induced by antinuclear antibodies. J. Autoimmun. 15: 15-20

26. Yasuda T, Takeshita H, Nakazato E, Nakajima T, Hosomi O, Nakashima Y and Kishi K (1998) Activity measurement for deoxyribonucleases I and II with picogram sensitivity based on DNA/SYBR Green I fluorescence. Anal. Biochem. 255: $274-276$ 